\title{
Host-Symbiont Interactions for Potentially Managing Heteropteran Pests
}

\author{
Simone Souza Prado ${ }^{1}$ and Tiago Domingues Zucchi² \\ ${ }^{1}$ Laboratório de Quarentena “Costa Lima”, Embrapa Meio Ambiente, Rodovia SP 340, Km 127,5, \\ Caixa Postal 69, 13820-000 Jaguariúna, SP, Brazil \\ ${ }^{2}$ Laboratório de Microbiologia Ambiental, Embrapa Meio Ambiente, Rodovia SP 340, Km 127,5, \\ Caixa Postal 69, 13820-000 Jaguariúna, SP, Brazil \\ Correspondence should be addressed to Simone Souza Prado, sprado@cnpma.embrapa.br
}

Received 27 February 2012; Accepted 27 April 2012

Academic Editor: Jeffrey R. Aldrich

Copyright ( $\odot 2012$ S. S. Prado and T. D. Zucchi. This is an open access article distributed under the Creative Commons Attribution License, which permits unrestricted use, distribution, and reproduction in any medium, provided the original work is properly cited.

\begin{abstract}
Insects in the suborder Heteroptera, the so-called true bugs, include over 40,000 species worldwide. This insect group includes many important agricultural pests and disease vectors, which often have bacterial symbionts associated with them. Some symbionts have coevolved with their hosts to the extent that host fitness is compromised with the removal or alteration of their symbiont. The first bug/microbial interactions were discovered over 50 years ago. Only recently, mainly due to advances in molecular techniques, has the nature of these associations become clearer. Some researchers have pursued the genetic modification (paratransgenesis) of symbionts for disease control or pest management. With the increasing interest and understanding of the bug/symbiont associations and their ecological and physiological features, it will only be a matter of time before pest/vector control programs utilize this information and technique. This paper will focus on recent discoveries of the major symbiotic systems in Heteroptera, highlighting how the understanding of the evolutionary and biological aspects of these relationships may lead to the development of alternative techniques for efficient heteropteran pest control and suppression of diseases vectored by Heteroptera.
\end{abstract}

\section{Introduction}

Insects are the most cosmopolitan, polyphagous, and varied living organisms on Earth, and many species are involved in some kind of symbiotic association with microorganisms, mainly bacteria $[1,2]$. Some insects associated with bacteria are also vectors of disease or are important crop pests which increase the relevance of these symbiotic interactions. The widespread distribution of insects may, in fact, be related to bacterial associations that allow host insects to exploit different nutritional sources, such as lignocellulose by termites, or to obtain essential nutrients from their symbionts, as in Buchnera aphidicola-aphid symbiosis $[3,4]$.

According to Moran [2], symbiosis is a "close relationship between two or more individuals." In insects, there are two major categories of symbiotic associations: obligatory and facultative [5]. Obligatory symbionts (also called primary symbionts) are nutritionally required for the survival of their insect hosts and usually inhabit specialized host cells.
On the other hand, secondary (also known as facultative) symbionts can be beneficial or cause incidental or deleterious infections [1]. The obligatory symbiont, B. aphidicola, for example, has never been cultured outside its host and is present intracellularly within specialized cells termed bacteriocytes $[1,5,6]$. Transovarial transmission is often the mode of symbiont transfer from one generation to another, which is a bottleneck that shapes the genome characteristics of the symbiont [7]. Phylogenetic analyses for certain insect families have shown that insects and primary endosymbionts have coevolved for millions of years after a single initial infection [5]. In contrast, secondary symbionts are nonessential to their hosts, may be free living, may not have specialized tissue localization, and occur extracellularly [8]. These secondary symbionts may provide benefits to their hosts such as tolerance to heat stress, compensation for loss of primary symbionts, and resistance to parasites and pathogens [9-13]. Conversely, facultative symbionts can negatively impact the growth, reproduction, and longevity 
of their hosts [14]. The evolutionary history of secondary endosymbionts often shows no coevolution with their hosts, suggesting multiple infections and/or horizontal transmission $[5,15]$. For example, the secondary endosymbiont of tsetse flies, Sodalis glossinidius, can be cultured in vitro and apparently has not coevolved with the insect hosts [16]. Sodalis glossinidius is closely related to bacterial pathogens of insects suggesting, in this case, that the symbiont evolved from an insect pathogen [16].

In Heteroptera, many species adversely affect humans and their environment by causing direct damage to the crops, or acting as vectors of disease to crops, domestic animals, and humans [17] (however, there are also many agriculturally beneficial predatory heteropterans). For over 50 years, it has been known that insects of the suborder Heteroptera (order Hemiptera) harbor symbiotic microorganisms; however, the significance of the relationship and their role in the host's ecology and evolution are only now being unraveled $[1,9]$. Symbiotic bacterial associations occur in all three hemipteran suborders: Sternorrhyncha (e.g., aphids, mealybugs, whiteflies, psyllids, etc.), Auchenorrhyncha (e.g., spittlebugs, planthoppers, leafhoppers, treehoppers, etc.), and Heteroptera (true bugs; Figure 1) [5, 18-21]. Experimental procedures for the phylogenetic tree analysis of Figure 1, the almost complete $16 \mathrm{~S}$ rRNA gene sequences $(1,300$ nucleotides) were obtained from GenBank database and were aligned manually using MEGA version 5 software [22]. Phylogenetic trees were inferred by using the maximumlikelihood [23], maximum-parsimony [24], and neighborjoining [25] tree-making algorithms drawn from the MEGA 5 and PHYML packages [22, 26]; an evolutionary distance matrix for the neighbor-joining algorithm was generated using the Jukes and Cantor [27] model. The topologies of the evolutionary trees were evaluated by a bootstrap analysis [28] of the neighbor-joining method based upon a 1,000 replicates using the MEGA 5 software.

Heteropteran symbionts are found in the gut lumen, as in Reduviidae, or in gastric caecae as in Acanthosomatidae, Alydidae, Coreidae, Parastrachiidae, Pentatomidae, Pyrrochoridae, Plataspidae, and Scutelleridae. As opposed to symbionts of Sternorrhyncha and Auchenorrhyncha, the symbionts of Heteroptera are not passed to the next generation from mother to offspring in a transovarial manner. The posthatch transmission mechanisms may involve egg surface contamination (= smearing on egg surface), coprophagy (= proctophagy: feeding on excrement), capsule transmission, or acquisition from the environment "de novo" every generation after the nymphs hatch $[1,18,19,21,29$ 39]. This curious mode of transmission is challenging to both the host and symbiont. In particular for the symbiont, external transmission may require high genome stability to prevent the loss of genes required for living outside the host in a variable environment, and the challenge for the host bugs is to reinoculate themselves each generation. These challenges may be responsible for the multiple acquisition of the symbiont or low cospeciation observed in Heteroptera $[21,29,40]$.

Not all heteropteran microbial associations are beneficial to the host; at times the bacteria may be pathogenic and reduce fitness (i.e., reproduction, mortality, and longevity) [41]. The beneficial and pathogenic aspects of symbiosis have been studied in the past, but now novel molecular approaches are being applied to these systems. With the advent of molecular approaches, it is increasingly clear that manipulation of symbiotic interactions can contribute to the development of new strategies for pest control, including the use of modified symbionts to control insects (paratrangenesis) [30,42], replacement of native symbionts with genetically modified symbionts via genetic drive [43, 44], and a technique called "incompatible insect" [45]. Additionally, Broderick et al. [46] showed that Bacillus thuringiensis, widely applied in biocontrol projects, only kills the lepidopteran larvae if the insects harbor a gut-associated microbial community, highlighting the importance of gutassociated bacteria to pest control.

\section{Reduviidae}

The vectors of the Chagas disease pathogen are bloodsucking Reduviidae in the subfamily Triatominae. For example, Rhodnius prolixus (Stal) is a blood-sucking triatomine that is a common vector of Chagas disease, the incurable illness damaging the heart and nervous system that afflicts millions of people in Central and South America [42]. This insect acquires its bacterial symbiont, Rhodococcus rhodnii, soon after the first instar bug hatches. In triatomines, generally, the aposymbiotic (without symbiont) first instar nymphs hatch and probe for their bacterial symbionts that are acquired orally through "contamination" by feces on or nearby egg masses [1,30,47]. This insect-symbiont association has been exploited by paratrangenesis, in which the symbiont has been genetically transformed to negatively interfere with the survivorship of the Chagas disease agent, Trypanosoma cruzi [48]. Genetically modified R. rhodnii symbionts expressing a selectable gene product were stably maintained in $R$. prolixus without deleterious effects on host survival and fitness, thereby substantiating the paratransgenic approach.

According to Hurwitz et al. [49] the paratransgenic strategy has been used with other vector-borne disease systems such as sandfly-mediated leishmaniasis and sharpshootermediated Pierce's disease [50-52]. Additionally, the authors highlight the main strategies for the success of the paratrangenesis strategy.

(1) In order to perform genetic manipulation, it is necessary that the symbiont can be cultured.

(2) The symbiont must be identified within a certain disease-transmitting vector.

(3) After the genetic manipulation, insect and symbiont fitness should not be negatively impacted.

(4) The transgene product expressed must interfere with pathogen development in the vector, but should not affect the fitness of the vector.

(5) The technique used to spread the genetically modified symbiont/commensal to naturally occurring vector populations should minimize the spread of 


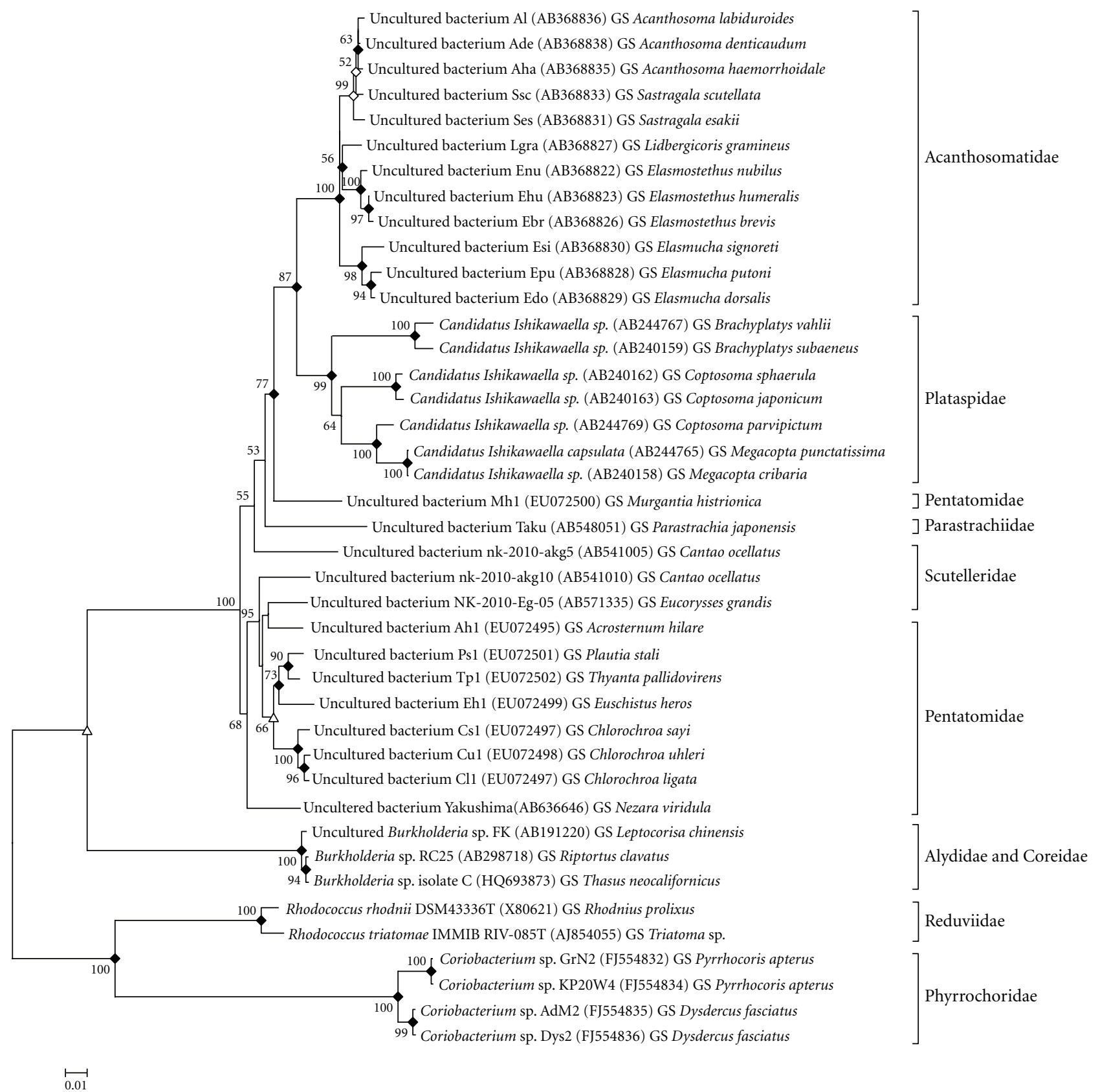

FIGURE 1: Neighbor-joining tree based on nearly complete 16S rRNA gene sequences (1,300 bp) showing phylogenetic relationships between gut symbionts (GS) of heteropteran species. Insect families are indicated after brackets. Black diamonds indicate branches of the tree that were also recovered with the maximum-likelihood and maximum-parsimony tree-making algorithms; white triangle and diamonds stand for branches that were recovered by the maximum-likelihood or by the maximum-parsimony tree-making algorithms, respectively. Numbers at the nodes are percentage bootstrap values based on a neighbor-joining analysis of 1,000 resampled datasets; only values above $50 \%$ are given. Bar 0.01 substitutions per nucleotide position.

the transgene to other organisms in the vector's environment, which include both the nontarget microbes inside the host/vector and other organisms that live in the same ecological niche.

\section{Acanthosomatidae}

This family, a member of the stink bug or shield bug Pentatomoidea superfamily, is characterized by social behavior, which features the maternal instinct to guard eggs and nymphs against possible predators [53]. The genetic and evolutionary characterization of the caeca-associated symbionts in 14 different species of Acanthosomatidae, representing a total of five genera (Elasmostethus, Lindbergicoris, Elasmucha, Sastragala, and Acanthosoma), has been elucidated [33]. Acanthosomatid bugs harbor extracellular symbionts of a specific clade of Gammaproteobacteria in midgut crypts. 
In Acanthosomatidae, both host and symbiont have cospeciated together, and the vertical symbiont transmission is via egg surface contamination [33].

\section{Alydidae and Coreidae}

Alydidae (called broad-headed bugs) and Coreidae (leaffooted bugs) are relatively small, principally herbivorous families. Alydid and coreid bugs feed mostly on seeds, less often on the phloem, of various plants; alydids also occasionally exhibit coprophagy and carrion feeding [17]. The broad-headed bugs, Riptortus clavatus (Thunberg), Leptocorisa chinensis (Dallas), and the giant mesquite bug Thasus neocalifornicus Brailovsky and Barrera, harbor symbionts of the Betaproteobacteria type in the genus Burkholderia. These insects acquire symbionts from the soil (i.e., horizontally) in each generation and harbor the bacteria in the lumen of crypts situated along the midgut $[15,54,55]$. Inoculation of aposymbiotic nymphs with cultured symbiotic microorganisms and comparison with aposymbiotic adults reared under sterile conditions suggest that the absence of the symbiont decreases host fitness [15, 54]. Moreover, phylogenetic analysis shows that the Burkholderia-like sequences from the digestive tract of $T$. neocalifornicus are closely related to those found in L. chinensis and R. clavatus, data acquired by amplifying the $1.5-\mathrm{kb}$ segment of the eubacterial $16 \mathrm{~S}$ rRNA gene [15].

\section{Parastrachiidae}

In Parastrachiidae (another pentatomoid family), Parastrachia japonensis Scott is monophagous, feeding of drupes of the deciduous tree Shoepfia jasminodora (Santalales: Olacaceae) [56]. The parastrachiid mother provides food for her nymphs, and the ensuing adults enter into diapause for 9 months, surviving only on water. Molecular phylogenetic analyses of $P$. japonensis symbionts revealed that they constitute a distinct phyletic line in the Gammaproteobacteria $16 \mathrm{~S}$ rRNA gene subclade. This parastrachiid symbiont has no close relatives, but is allied with gut symbionts of acanthosomatid and plataspid bugs, as well as with endocellular symbionts of sharpshooters, tsetse flies, and aphids [36]. According to Kashima et al. [57], this symbiont might be involved in the uric acid recycling system due to the increased mortality of the adults when they were treated with antibiotic during the nonfeeding period.

\section{Pentatomidae}

Within Heteroptera, the Pentatomidae (the true "stink bugs") is one of the largest families with over 4000 species [17]. Many pentatomid insects are polyphagous, feeding on a diverse range of plants. Stink bugs are economically important pests throughout the world on a multitude of crops, including soybeans, rice, pecan, cocoa, and macadamia nuts to name a few $[17,58]$. They can cause direct and indirect damage, as can other heteropteran, by feeding on plant tissue with needle-like stylets, injecting digestive enzymes into plant tissue, or providing free access

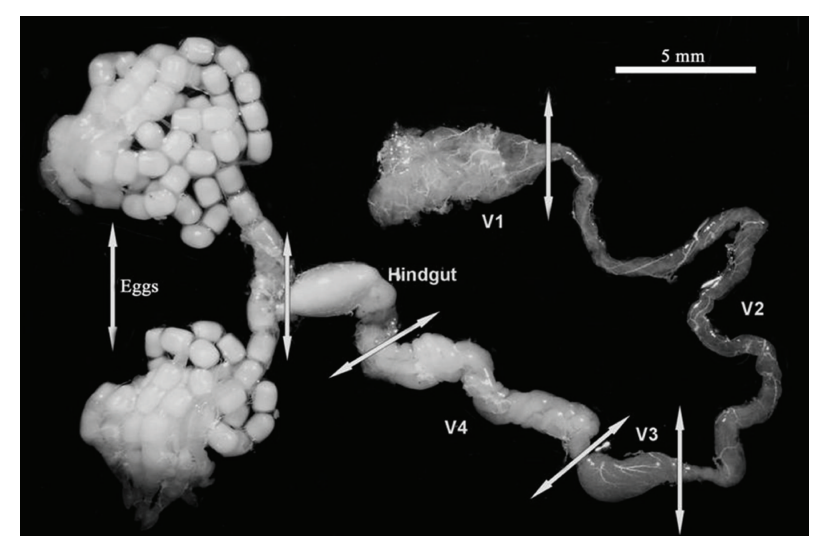

Figure 2: Detailed figure of the midgut of Nezara viridula divided into four ventricles. V4 is the gastric caeca, where the symbionts are located [21].

to microbial infection $[17,59]$. The economic importance of stink bugs is magnified as they are usually difficult to control [60]. Recently, it was shown that the stink bugs, Acrosternum hilare (Say), Chlorochroa ligata (Say), Chlorochroa sayi (Stal), Chlorochroa uhleri (Stal), Dichelops melacanthus (Dallas), Edessa meditabunda (F.), Euschistus heros (Fabricius), Loxa deducta Walker, Murgantia histrionica (Hahn), Nezara viridula (L.), Pellaea stictica (Dallas, 1851), Piezodorus guildinii (Westwood), Plautia stali Scott, Thyanta pallidovirens (Stal), and, Thyanta perditor (F.) are associated with plant pathogens (Pantoea spp.) contained in the gastric caecal region (ventricula 4; Figures 2 and 3 ) of their midguts $[21,34,35,40,61$, Prado, S.S. unpublished data]. In general, stink bug symbionts are polyphyletic, although some degree of monophyly has also been observed suggesting that the symbionts were probably acquired and occasionally replaced by other bacteria over evolutionary time $[34,35]$. Smearing of symbionts on the egg surface by ovipositing females and subsequent acquisition of the symbiont by aposymbiotic first instar nymphs appears to be the mechanism of vertical transmission.

The cosmopolitan pentatomid, Nezara viridula, is both generally and obligatorily associated with a gut symbiont; however, it seems that the type and duration of the association is somewhat different between populations based on the geographical region where the insect is found [20, 21,39]. At $30^{\circ} \mathrm{C}, \mathrm{N}$. viridula's symbiont maintenance is affected and insect development is accelerated [40]. Insects free of the symbionts reared at $20^{\circ} \mathrm{C}$ had longer mean nymphal developmental time, and females never laid eggs $[21,40]$.

In addition, $P$. stali, when deprived of its gut-associated symbiont, has a slower developmental time than individuals with the symbiont [29]. For A. hilare, the elimination of the symbiont by surface sterilization of egg masses negatively impacted development and reproduction [35]. Conversely, the absence of $M$. histrionica's gut symbiont seems to have no effect on the development of the insect host; however, when both species (A. hilare and M. histrionica) were reared at $30^{\circ} \mathrm{C}$, each lost their respective symbiont [61]. 


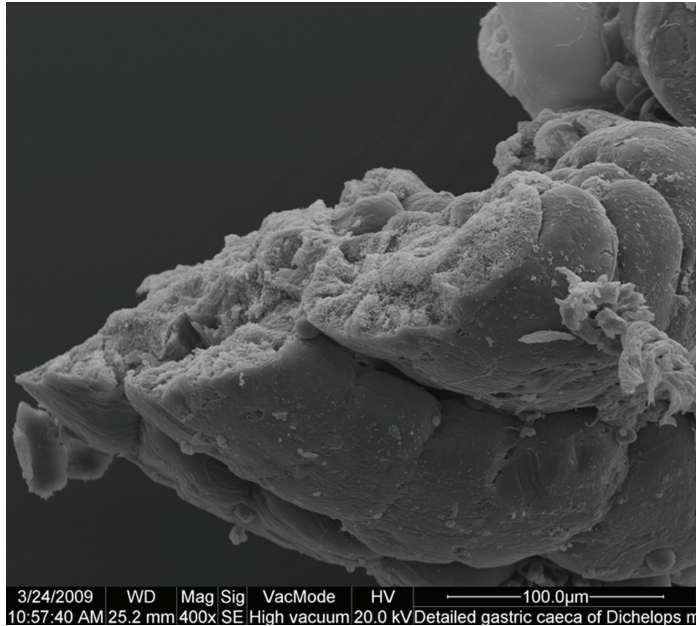

(a)

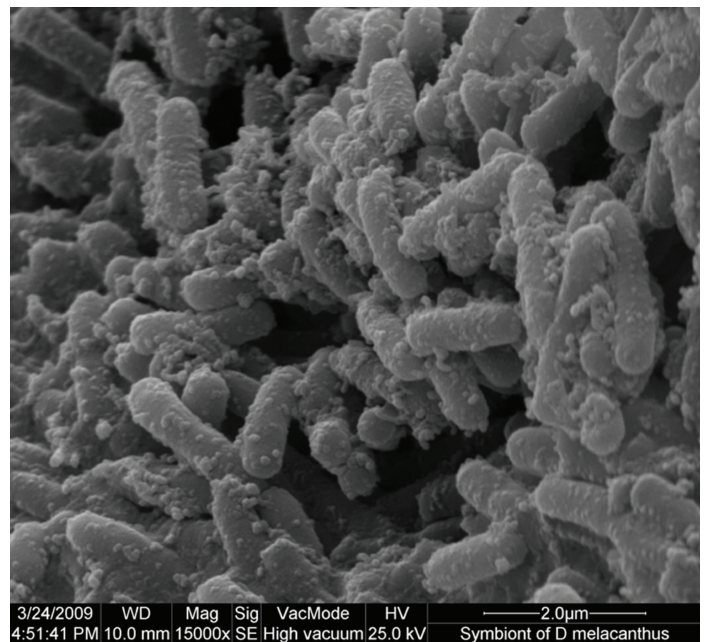

(c)

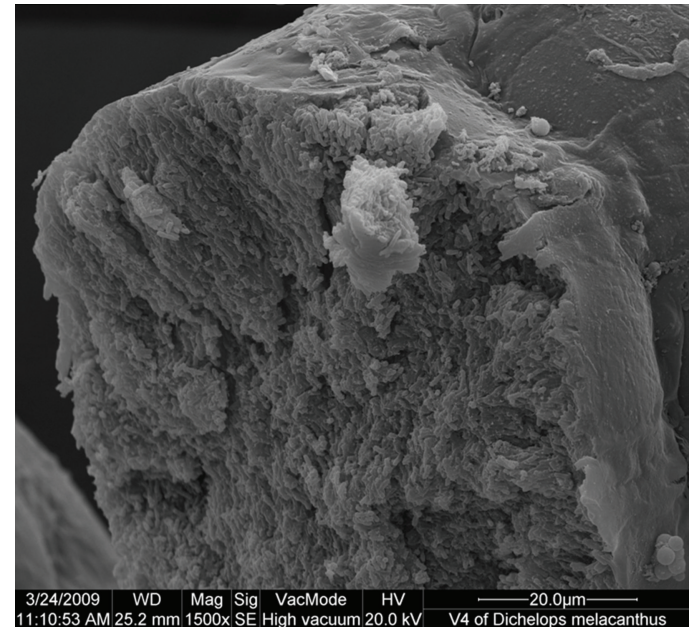

(b)

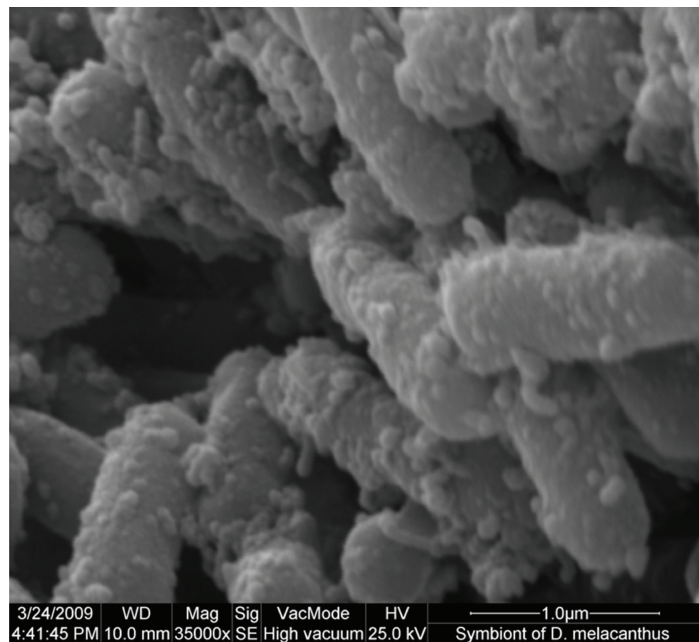

(d)

FIGURE 3: Detailed figure of scan electron microscopy (SEM) of the gastric caeca of Dichelops melacanthus in (a), detail of the amount of bacteria inside the gastric caeca in (b), and bacteria detail in (c) and (d).

The impact of surface sterilization on the maintenance of the symbionts and on the development of E. heros, D. melacanthus, and P. stictica is being evaluated by Prado et al. (unpublished). Data thus far has shown that a decrease in host fitness was associated with, and probably mediated by, symbiont loss at $30^{\circ} \mathrm{C}$. This suggests that, not only egg mass sterilization, but also higher temperature may affect population performance of the insects directly or indirectly through mediated effects on their mutualists $[35,61]$. The role of these vertically transmitted pentatomid gut symbionts, therefore, appears to vary for different bug host species. For instance, the cabbage stink bugs, Eurydema rugosa Motschulsky and Eurydema dominulus (Scopoli), also have symbionts associated with their gastric caecae; absence of the caeca-associated symbiont due to surface sterilization of egg masses caused retarded growth, reduced body weight, and abnormal body color [62].

Recently, using genus-specific primers and appropriate PCR conditions, Zucchi et al. [63] characterized an earlier unnoticed community of actinobacteria inhabiting the gastric caeca of several pentatomid species (Table 1). Although only a few insects species have been reported associated with Actinobacteria [64], the best-known case involving nutrient provision (see Section 2), studies on pentatomids have pointed to an alternative beneficial association in which the actinobacteria produce an antibiotic barrier against pathogens $[65,66]$. The role of these actinobacteria in the midgut of the stink bug is still unknown, but Zucchi et al. [63] speculate that the actinobacteria byproducts may regulate the gastric caecal bacterial community.

\section{Phyrrochoridae}

There is at least 262 pyrrochorid species distributed in 29 genera, with Dysdercus being the most important and largest genus [17]. These bugs are called cotton stainers because their excreta, plus the disease organisms they admit, stain cotton fiber. An actinobacterium, Coriobacterium glomerans, has been described as the extracellular gut-associated 
Table 1: Actinobacteria diversity inhabiting the midgut of Pentatomidae.

\begin{tabular}{|c|c|c|}
\hline Family & Genus & Host \\
\hline Actinomycetaceae & Actinomyces spp. & Thyanta perditor \\
\hline Brevibacteriaceae & Brevibacterium spp. & Dichelops melacanthus \\
\hline \multirow{3}{*}{ Corynebacteriaceae } & \multirow{3}{*}{ Corynebacterium spp. } & Dichelops melacanthus \\
\hline & & Edessa meditabunda \\
\hline & & Thyanta perditor \\
\hline \multirow{3}{*}{ Dietziaceae } & \multirow{3}{*}{ Dietizia spp. } & Dichelops melacanthus \\
\hline & & Loxa deducta \\
\hline & & Pellea stictica \\
\hline \multirow{2}{*}{ Intransporangiaceae } & \multirow{2}{*}{ Ornithinimicrobium spp. } & Loxa deducta \\
\hline & & Pellea stictica \\
\hline Kineosporiaceae & Kineococcus spp. & Dichelops melacanthus \\
\hline Microbacteriaceae & Microbacterium spp. & Edessa meditabunda \\
\hline \multirow{3}{*}{ Micrococcaceae } & Arthrobacter spp. & Edessa meditabunda \\
\hline & \multirow{2}{*}{ Citrococcus spp. } & Dichelops melacanthus \\
\hline & & Edessa meditabunda \\
\hline \multirow{4}{*}{ Mycobacteriaceae } & \multirow{4}{*}{ Mycobacterium spp. } & Loxa deducta \\
\hline & & Pellea stictica \\
\hline & & Piezodorus guildinii \\
\hline & & Thyanta perditor \\
\hline \multirow{2}{*}{ Propionibacteriaceae } & \multirow{2}{*}{ Propionibacterium spp. } & Dichelops melacanthus \\
\hline & & Piezodorus guildinii \\
\hline Streptomycetaceae & Streptomyces spp. & Nezara viridula \\
\hline
\end{tabular}

Source: modified from Zucchi et al. [63].

symbiont in Pyrrhocoris apterus (L.) and Dysdercus fasciatus Sign. [32, 67, 68]. Recently, Kaltenpoth et al. [32] showed that the bacterial symbionts are located mainly in the third part of the midgut (V 3), with cells found connected to the epithelium and swimming freely in the gut. The symbionts are primarily transmitted vertically by egg smearing, but horizontal transmission also occurs [32]. The bacterial cells can form long chains in the gut of the insects, where they are assumed to aid in digestion [67].

\section{Plataspidae}

Insects of this family are almost entirely from the tropical old world most species are Oriental and; this is one of a few groups that feed most of the time on legumes [17]. The Japanese common plataspid, Megacopta punctatissima (Montandon), harbors the bacterial symbiont Candidatus Ishikawaella capsulata in its gastric caeca [19]. Fukatsu and Hosokawa [18] showed that after hatching, the aposymbiotic first instar nymphs immediately probe small brownish capsules attached to the eggs masses laid by the females in order to acquire their symbiont $[18,19,41]$. In addition, Hosokawa et al. [19] used phylogenetic reconstruction to show that both insect and symbiont have undergone cospeciation and when deprived of its symbiont, $M$. punctatissima's growth and survival are negatively influenced $[18,19,41]$. The plataspid bug, Megacopta cribraria (Fabricius), also has an obligatory relationship with its primary endosymbiont, which is similar to that first described for M. punctatissima [69]. Recently, Hosokawa et al. [41] showed by experimentally exchanging the obligatory gut-associated symbiont between M. punctatissima and M. cribraria, that the success of the important pest species on legumes (M. punctatissima) was negatively impacted due to high nymphal mortality before or upon hatching. Conversely, M. cribraria, which is considered a nonpest species of the legume crop, when carrying $M$. punctatissima's obligatory symbiont, exhibited the attributes of the naturally pestiferous species. These exciting findings raise new hypotheses on the evolutionary origin of an insect pest, which may lead to the development of alternative methods to control and manage species considered pests [41].

\section{Scutelleridae}

Within the Pentatomoidea, this family (commonly called shield bugs) is most closely related to Pentatomidae. All scutellerids are phytophagous, but only a few have been reported as pests [17]. The giant jewel shield bugs, Cantao ocellatus (Thunberg) and Eucorysses grandis (Thunberg), possess a gammaproteobacterial primary gut symbiont and a Sodalis-allied secondary symbiont $[37,38]$. The specific 
bacterium from E. grandis was consistently identified in insects from five different geographic regions and was detected in $100 \%$ of the insects surveyed from three host populations. Molecular phylogenetic analysis clearly showed that the primary gut-associated symbiont of $E$. grandis constitutes a distinct lineage in the Gammaproteobacteria, and is closely related neither to the gut symbiont associated with C. ocellatus, nor to gut symbionts of other stink bugs, suggesting that scutellerid symbionts have multiple evolutionary origins [38].

\section{Concluding Remarks}

In this paper, we reviewed major trends in symbiotic association for diverse members of the Heteroptera. These interactions have been primarily studied for their ecological interest regarding insect development. In the past decade, it has become increasingly clear that exploiting these relationships may be a fruitful alternative type of biological control; paratrangenesis [42] and specific elimination of the essential bacteria of the pest or vector insect [70] demonstrated promising results.

Endosymbiotic bacteria of insects have received considerable attention in the past few decades. Many studies focused on the intimate associations of intracellular symbionts, their hosts and the degree of mutual interdependence of these symbioses. Most of these studies focused on obligatory symbionts that are difficult or so far impossible to cultivate. Successful attempts at pest control or disease management, such as those demonstrated by the paratrangenesis of the endosymbiont actinobacteria from triatomine species, should become more common once efforts to identify other bacterial symbionts for other heteropteran hosts are more successful, particularly with secondary symbionts. Furthermore, recent studies have shown that extracellular gut symbionts of insects can engage in symbiotic interactions of similar intimacy and specificity with their hosts, and may exhibit similar evolutionary and genomic consequences of the symbiotic lifestyle [19].

There may also be negative impacts on the symbiont-host relationship caused by global warming changes and, consequently, interference in insect survivorship and ecology from elevated global temperatures, encouraging more research on these associations $[9,12,14,15,71]$.

At the time of writing, only a few examples of insectmicroorganism associations are effectively being explored for control of pests or human diseases. This is still an open area of research with great potential for control of insect pests and vectors of disease, as the cases mentioned earlier using the paratransgenic strategy in the systems of sandfly/leishmaniasis and sharpshooter/Pierce's disease represent [50-52]. In fact, it is only recently that considerable information has been gathered to permit the design of alternative methods of control. Studies on different bacterial groups, such as actinobacteria, reminds us how intricate and complex the associations between stink bugs and microorganisms are. Further comprehension of their biological, physiological, and ecological features is necessary to have a better picture of the evolution of these interactions and to devise a more effective pest and disease control programs.

\section{Acknowledgments}

The authors would like to thank Jacqueline Robson and Mandy Anhalt for comments and help with the English revision. They also would like to thank the help of Dr. Celia Andrade and Osvaldo Capello from Universidade Estadual de Londrina (UEL), PR, Brazil, with the scan electron microscopy (SEM). Additionally, the authors would like to thank Dr. Jeffrey Aldrich (USDA-ARS) and the 3 anonymous reviewers that revised and positively contributed with this paper.

\section{References}

[1] P. Buchner, Endosymbiosis of Animals with Plant Microorganisms, Interscience, New York, NY, USA, 1965.

[2] N. A. Moran, "Symbiosis," Current Biology, vol. 16, no. 20, pp. R866-R871, 2006.

[3] M. Ohkuma, "Termite symbiotic systems: efficient biorecycling of lignocellulose," Applied Microbiology and Biotechnology, vol. 61, no. 1, pp. 1-9, 2003.

[4] A. E. Douglas, "Nutritional interactions in insect-microbial symbioses: aphids and their symbiotic bacteria Buchnera," Annual Review of Entomology, vol. 43, pp. 17-37, 1998.

[5] P. Baumann, "Biology of bacteriocyte-associated endosymbionts of plant sap-sucking insects," Annual Review of Microbiology, vol. 59, pp. 155-189, 2005.

[6] S. Shigenobu, H. Watanabe, M. Hattori, Y. Sakaki, and H. Ishikawa, "Genome sequence of the endocellular bacterial symbiont of aphids Buchnera sp. APS," Nature, vol. 407, no. 6800, pp. 81-86, 2000.

[7] M. L. Thao, P. J. Gullan, and P. Baumann, "Secondary ( $\gamma$ Proteobacteria) endosymbionts infect the primary $(\beta$-Proteobacteria) endosymbionts of mealybugs multiple times and coevolve with their hosts," Applied and Environmental Microbiology, vol. 68, no. 7, pp. 3190-3197, 2002.

[8] C. Dale and I. Maudlin, "Sodalis gen. nov. and Sodalis glossinidius sp. nov., a microaerophilic secondary endosymbiont of the tsetse fly Glossina morsitans morsitans," International Journal of Systematic Bacteriology, vol. 49, no. 1, pp. 267-275, 1999.

[9] R. Koga, T. Tsuchida, and T. Fukatsu, "Changing partners in an obligate symbiosis: a facultative endosymbiont can compensate for loss of the essential endosymbiont Buchnera in an aphid," Proceedings of the Royal Society B, vol. 270, no. 1533, pp. 2543-2550, 2003.

[10] C. B. Montllor, A. Maxmen, and A. H. Purcell, "Facultative bacterial endosymbionts benefit pea aphids Acyrthosiphon pisum under heat stress," Ecological Entomology, vol. 27, no. 2, pp. 189-195, 2002.

[11] K. M. Oliver, N. A. Moran, and M. S. Hunter, "Variation in resistance to parasitism in aphids is due to symbionts not host genotype," Proceedings of the National Academy of Sciences of the United States of America, vol. 102, no. 36, pp. 12795-12800, 2005.

[12] J. A. Russell and N. A. Moran, "Costs and benefits of symbiont infection in aphids: variation among symbionts and across 
temperatures," Proceedingsof the Royal Society B, vol. 273, no. 1586, pp. 603-610, 2006.

[13] C. L. Scarborough, J. Ferrari, and H. C. J. Godfray, "Ecology: aphid protected from pathogen by endosymbiont," Science, vol. 310, no. 5755, p. 1781, 2005.

[14] D. Q. Chen, C. B. Montllor, and A. H. Purcell, "Fitness effects of two facultative endosymbiotic bacteria on the pea aphid, Acyrthosiphon pisum, and the blue alfalfa aphid, A. kondoi," Entomologia Experimentalis et Applicata, vol. 95, no. 3, pp. 315-323, 2000.

[15] Y. Kikuchi, X. Y. Meng, and T. Fukatsu, "Gut symbiotic bacteria of the genus Burkholderia in the broad-headed bugs Riptortus clavatus and Leptocorisa chinensis (Heteroptera: Alydidae)," Applied and Environmental Microbiology, vol. 71, no. 7, pp. 4035-4043, 2005.

[16] C. Dale, S. A. Young, D. T. Haydon, and S. C. Welburn, "The insect endosymbiont Sodalis glossinidius utilizes a type III secretion system for cell invasion," Proceedings of the National Academy of Sciences of the United States of America, vol. 98, no. 4, pp. 1883-1888, 2001.

[17] C. W. Schaefer and A. R. Panizzi, Heteroptera of Economic Importance, CRC Press, Boca Raton, Fla, USA, 2000.

[18] T. Fukatsu and T. Hosokawa, "Capsule-transmitted gut symbiotic bacterium of the Japanese common plataspid stinkbug, Megacopta punctatissima," Applied and Environmental Microbiology, vol. 68, no. 1, pp. 389-396, 2002.

[19] T. Hosokawa, Y. Kikuchi, N. Nikoh, M. Shimada, and T. Fukatsu, "Strict host-symbiont cospeciation and reductive genome evolution in insect gut bacteria," PLoS Biology, vol. 4, no. 10, pp. 1841-1851, 2006.

[20] E. Hirose, A. R. Panizzi, J. T. De Souza, A. J. Cattelan, and J. R. Aldrich, "Bacteria in the gut of Southern green stink bug (Heteroptera: Pentatomidae)," Annals of the Entomological Society of America, vol. 99, no. 1, pp. 91-95, 2006.

[21] S. S. Prado, D. Rubinoff, and R. P. P. Almeida, "Vertical transmission of a pentatomid caeca-associated symbiont," Annals of the Entomological Society of America, vol. 99, no. 3, pp. 577$585,2006$.

[22] K. Tamura, D. Peterson, N. Peterson, G. Stecher, M. Nei, and S. Kumar, "MEGA5: molecular evolutionary genetics analysis using maximum likelihood, evolutionary distance, and maximum parsimony methods," Molecular Biology and Evolution, vol. 28, no. 10, pp. 2731-2739, 2011.

[23] J. Felsenstein, "Evolutionary trees from DNA sequences: a maximum likelihood approach," Journal of Molecular Evolution, vol. 17, no. 6, pp. 368-376, 1981.

[24] W. M. Fitch, "Toward defining the course of evolution: minimum change for specific tree topology," Systematic Zoology, vol. 20, no. 4, pp. 406-416, 1971.

[25] N. Saitou and M. Nei, "The neighbor-joining method: a new method for reconstructing phylogenetic trees," Molecular Biology and Evolution, vol. 4, no. 4, pp. 406-425, 1987.

[26] S. Guindon and O. Gascuel, "A simple, fast, and accurate algorithm to estimate large phylogenies by maximum likelihood," Systematic Biology, vol. 52, no. 5, pp. 696-704, 2003.

[27] T. H. Jukes and C. R. Cantor, "Evolution of protein molecules," in Mammalian Protein Metabolism, H. N. Munro, Ed., vol. 3, pp. 21-123, Academic Press, New York, NY, USA, 1969.

[28] J. Felsenstein, "Confidence limits on phylogenies: an approach using the bootstrap," Evolution, vol. 39, pp. 783-791, 1985.

[29] Y. Abe, K. Mishiro, and M. Takanashi, "Symbiont of brownwinged green bug Plautia stali Scott," The Japanese Journal of Applied Entomology and Zoology, vol. 39, pp. 109-115, 1995.
[30] R. V. Durvasula, A. Kroger, M. Goodwin et al., "Strategy for introduction of foreign genes into field populations of Chagas disease vectors," Annals of the Entomological Society of America, vol. 92, no. 6, pp. 937-943, 1999.

[31] T. Hosokawa, Y. Kikuchi, Y. M. Xien, and T. Fukatsu, "The making of symbiont capsule in the plataspid stinkbug Megacopta punctatissima," FEMS Microbiology Ecology, vol. 54, no. 3, pp. 471-477, 2005.

[32] M. Kaltenpoth, S. A. Winter, and A. Kleinhammer, "Localization and transmission route of Coriobacterium glomerans, the endosymbiont of pyrrhocorid bugs," FEMS Microbiology Ecology, vol. 69, no. 3, pp. 373-383, 2009.

[33] Y. Kikuchi, T. Hosokawa, N. Nikoh, X. Y. Meng, Y. Kamagata, and T. Fukatsu, "Host-symbiont co-speciation and reductive genome evolution in gut symbiotic bacteria of acanthosomatid stinkbugs," BMC Biology, vol. 7, article 2, 2009.

[34] S. S. Prado and R. P. P. Almeida, "Phylogenetic placement of pentatomid stink bug gut symbionts," Current Microbiology, vol. 58, no. 1, pp. 64-69, 2009.

[35] S. S. Prado and R. P. P. Almeida, "Role of symbiotic gut bacteria in the development of Acrosternum hilare and Murgantia histrionica," Entomologia Experimentalis et Applicata, vol. 132, no. 1, pp. 21-29, 2009.

[36] T. Hosokawa, Y. Kikuchi, N. Nikon, X. Y. Meng, M. Hironaka, and T. Fukatsu, "Phylogenetic position and peculiar genetic traits of a midgut bacterial symbiont of the stinkbug Parastrachia japonensis," Applied and Environmental Microbiology, vol. 76, no. 13, pp. 4130-4135, 2010.

[37] N. Kaiwa, T. Hosokawa, Y. Kikuchi et al., "Primary gut symbiont and secondary, sodalis-allied symbiont of the scutellerid stinkbug Cantao ocellatus," Applied and Environmental Microbiology, vol. 76, no. 11, pp. 3486-3494, 2010.

[38] N. Kaiwa, T. Hosokawa, Y. Kikuchi et al., "Bacterial symbionts of the giant jewel stinkbug Eucorysses grandis (Hemiptera: Scutelleridae)," Zoological Science, vol. 28, no. 3, pp. 169-174, 2011.

[39] A. Tada, Y. Kikuchi, T. Hosokawa, D. L. Musolin, K. Fujisaki, and T. Fukatsu, "Obligate association with gut bacterial symbiont in Japanese populations of the Southern green stinkbug Nezara viridula (Heteroptera: Pentatomidae)," Applied Entomology and Zoology, vol. 46, pp. 483-488, 2011.

[40] S. S. Prado, M. Golden, P. A. Follett, M. P. Daugherty, and R. P. P. Almeida, "Demography of gut symbiotic and aposymbiotic Nezara viridula L. (Hemiptera: Pentatomidae)," Environmental Entomology, vol. 38, no. 1, pp. 103-109, 2009.

[41] T. Hosokawa, Y. Kikuchi, M. Shimada, and T. Fukatsu, "Obligate symbiont involved in pest status of host insect," Proceedings of the Royal Society B, vol. 274, no. 1621, pp. 19791984, 2007.

[42] C. B. Beard, C. Cordon-Rosales, and R. V. Durvasula, "Bacterial symbionts of the Triatominae and their potential use in control of Chagas disease transmission," Annual Review of Entomology, vol. 47, pp. 123-141, 2002.

[43] S. L. Dobson, "Reversing Wolbachia-based population replacement," Trends in Parasitology, vol. 19, no. 3, pp. 128-133, 2003.

[44] S. P. Sinkins and F. Gould, "Gene drive systems for insect disease vectors," Nature Reviews Genetics, vol. 7, no. 6, pp. 427435, 2006.

[45] S. Zabalou, M. Riegler, M. Theodorakopoulou, C. Stauffer, C. Savakis, and K. Bourtzis, "Wolbachia-induced cytoplasmic incompatibility as a means for insect pest population control," Proceedings of the National Academy of Sciences of the United States of America, vol. 101, no. 42, pp. 15042-15045, 2004. 
[46] N. A. Broderick, K. F. Raffa, and J. Handelsman, "Midgut bacteria required for Bacillus thuringiensis insecticidal activity," Proceedings of the National Academy of Sciences of the United States of America, vol. 103, no. 41, pp. 15196-15199, 2006.

[47] P. G. Lawyer and P. V. Perkins, "Leishmaniasis and trypanosomiasis," in Medical Entomology, B. F. Eldridge and J. D. Edman, Eds., pp. 231-298, Kluwer Academic, Dodrecht, The Netherlands, 2000.

[48] R. V. Durvasula, R. K. Sundaram, C. Cordon-Rosales, P. Pennington, and C. B. Beard, "Rhodnius prolixus and its symbiont, Rhodococcus rhodnii: a model for paratransgenic control of disease transmission," in Insect Symbiosis, K. Bourtzis and T. A. Miller, Eds., pp. 83-95, CRC Press, Boca Raton, Fla, USA, 2003.

[49] I. Hurwitz, A. Fieck, N. Klein, C. Jose, A. Kang, and R. Durvasula, "A paratransgenic strategy for the control of Chagas disease," 2011, http://www.hindawi.com/journals/psyche/aip/178930.pdf.

[50] T. Miller, C. Lauzon, D. Lampe, R. Durvasula, and S. Matthews, "Paratransgenesis applied to insect-transmitted disease: the Pierce's disease case," in Insect Symbiosis 2, T. Miller and K. Bourtzis, Eds., 2006.

[51] H. Hillesland, A. Read, B. Subhadra et al., "Identification of aerobic gut bacteria from the kala azar vector, Phlebotomus argentipes: a platform for potential paratransgenic manipulation of sand flies," American Journal of Tropical Medicine and Hygiene, vol. 79, no. 6, pp. 881-886, 2008.

[52] I. Hurwitz, H. Hillesland, A. Fieck, P. Das, and R. Durvasula, "The paratransgenic sand fly: a platform for control of Leishmania transmission," Parasites and Vectors, vol. 4, no. 1, article 82, 2011.

[53] R. T. Schuh and J. A. Slater, True Bugs of the World (Hemiptera: Heteroptera), Cornell University Press, New York, NY, USA, 1995.

[54] Y. Kikuchi, T. Hosokawa, and T. Fukatsu, "Insect-microbe mutualism without vertical transmission: a stinkbug acquires a beneficial gut symbiont from the environment every generation," Applied and Environmental Microbiology, vol. 73, no. 13, pp. 4308-4316, 2007.

[55] S. Olivier-Espejel, Z. L. Sabree, K. Noge, and J. X. Becerra, "Gut microbiota in nymph and adults of the giant mesquite bug (Thasus neocalifornicus) (Heteroptera: Coreidae) is dominated by Burkholderia acquired de novo every generation," Environmental Entomology, vol. 40, no. 5, pp. 1102-1110, 2011.

[56] N. Gyotoku and S. Tachikawa, "Life history of Parastrachia japonensis (Scott) Cydnidae: Sehirinae," Rostria, vol. 33, pp. 359-368, 1980.

[57] T. Kashima, T. Nakamura, and S. Tojo, "Uric acid recycling in the shield bug, Parastrachia japonensis (Hemiptera: Parastrachiidae), during diapause," Journal of Insect Physiology, vol. 52, no. 8, pp. 816-825, 2006.

[58] C. J. Davis, "The introduction, propagation, liberation and establishment of parasites to control Nezara viridula variety smaragdula (Fabricius) in Hawaii (Heteroptera: Pentatomidae)," Proceedings of the Hawaiian Entomological Society, vol. 18, pp. 369-375, 1964.

[59] V. P. Jones and L. C. Caprio, "Biology and control of insect pests attacking macadamia nuts in Hawaii," Proceedings of Hawaii Macadamia Nut Association, vol. 18, pp. 24-36, 1990.

[60] K. M. Daane, G. Y. Yokota, R. Krugner et al., "Large bugs damage pistachio nuts most severely during midseason," California Agriculture, vol. 59, pp. 95-102, 2005.
[61] S. S. Prado, K. Y. Hung, M. P. Daugherty, and R. P. P. Almeida, "Indirect effects of temperature on stink bug fitness, via maintenance of gut-associated symbionts," Applied and Environmental Microbiology, vol. 76, no. 4, pp. 1261-1266, 2010.

[62] Y. Kikuchi, T. Hosokawa, N. Nikoh, and T. Fukatsu, "Gut symbiotic bacteria in the cabbage bugs Eurydema rugosa and Eurydema dominulus (Heteroptera: Pentatomidae)," Applied Entomology and Zoology, vol. 47, no. 1, pp. 1-8, 2012.

[63] T. D. Zucchi, S. S. Prado, and F. L. Consoli, "The gastric caeca as a house for actinomycetes," BMC Microbiology, vol. 12, no. 1, article 101, 2012.

[64] M. Kaltenpoth, "Actinobacteria as mutualists: general healthcare for insects?" Trends in Microbiology, vol. 17, no. 12, pp. 529-535, 2009.

[65] M. Kaltenpoth, W. Goettler, C. Dale et al., "'Candidatus Streptomyces philanthi, an endosymbiotic streptomycete in the antennae of Philanthus digger wasps," International Journal of Systematic and Evolutionary Microbiology, vol. 56, no. 6, pp. 1403-1411, 2006.

[66] T. D. Zucchi, A. S. Guidolin, and F. L. Consoli, "Isolation and characterization of actinobacteria ectosymbionts from Acromyrmex subterraneus brunneus (Hymenoptera, Formicidae)," Microbiological Research, vol. 166, no. 1, pp. 68-76, 2011.

[67] F. Haas and H. Konig, "Characterisation of an anaerobic symbiont and the associated aerobic bacterial flora of Pyrrhocoris apterus (Heteroptera: Pyrrhocoridae)," FEMS Microbiology Letters, vol. 45, no. 2, pp. 99-106, 1987.

[68] F. Haas and H. Konig, "Coriobacterium glomerans gen. nov., sp. nov. from the intestinal tract of the red soldier bug," International Journal of Systematic Bacteriology, vol. 38, no. 4, pp. 382-384, 1988.

[69] T. M. Jenkins and T. D. Eaton, "Population genetic baseline of the first plataspid stink bug symbiosis (Hemiptera: Heteroptera: Plataspidae) reported in North America," Insects, vol. 2, pp. 264-672, 2011.

[70] A. E. Douglas, "Symbiotic microorganisms: untapped resources for insect pest control," Trends in Biotechnology, vol. 25, no. 8, pp. 338-342, 2007.

[71] C. Ohtaka and H. Ishikawa, "Effects of heat treatment on the symbiotic system of an aphid mycetocyte," Symbiosis, vol. 11, pp. 19-30, 1991. 

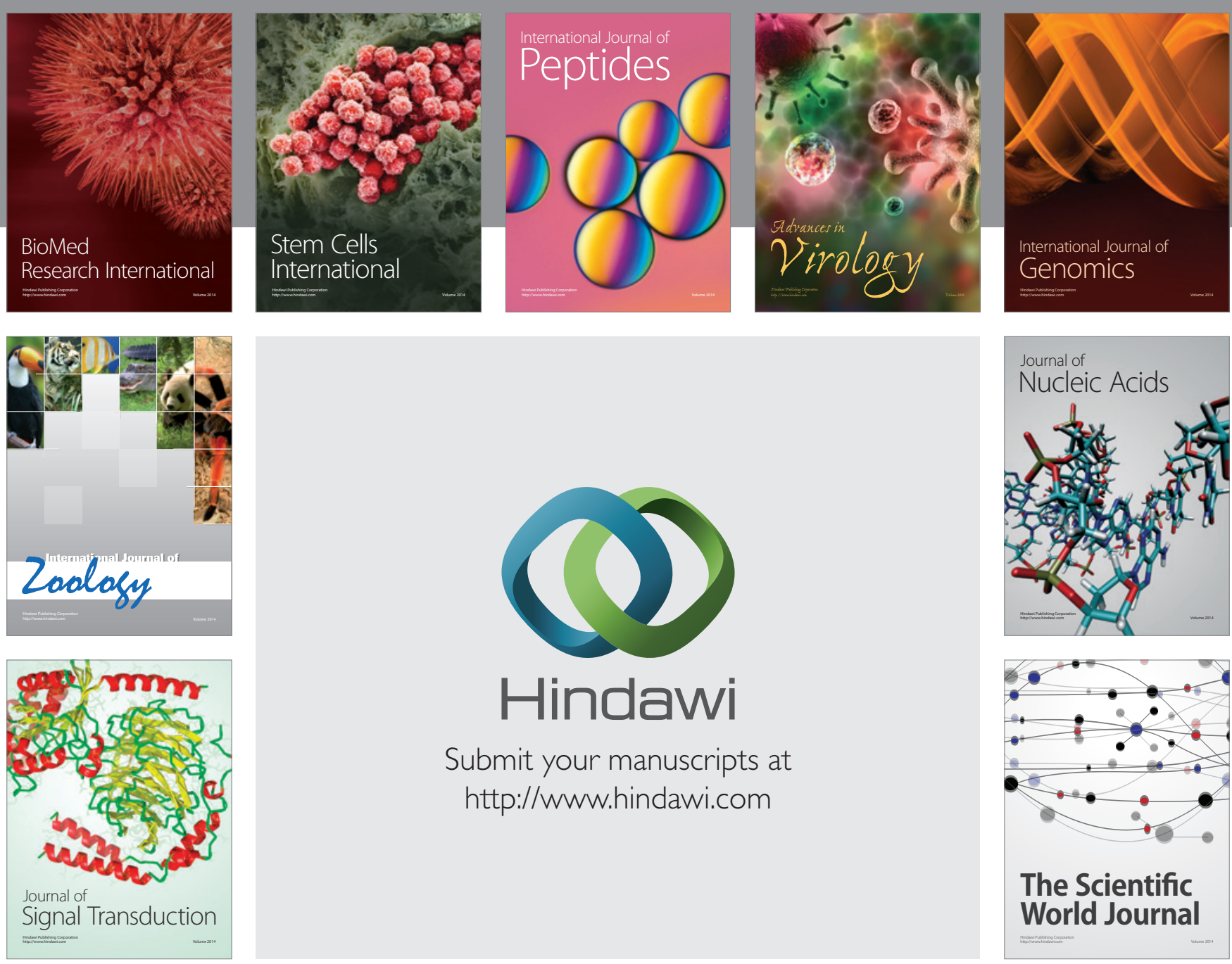

Submit your manuscripts at

http://www.hindawi.com
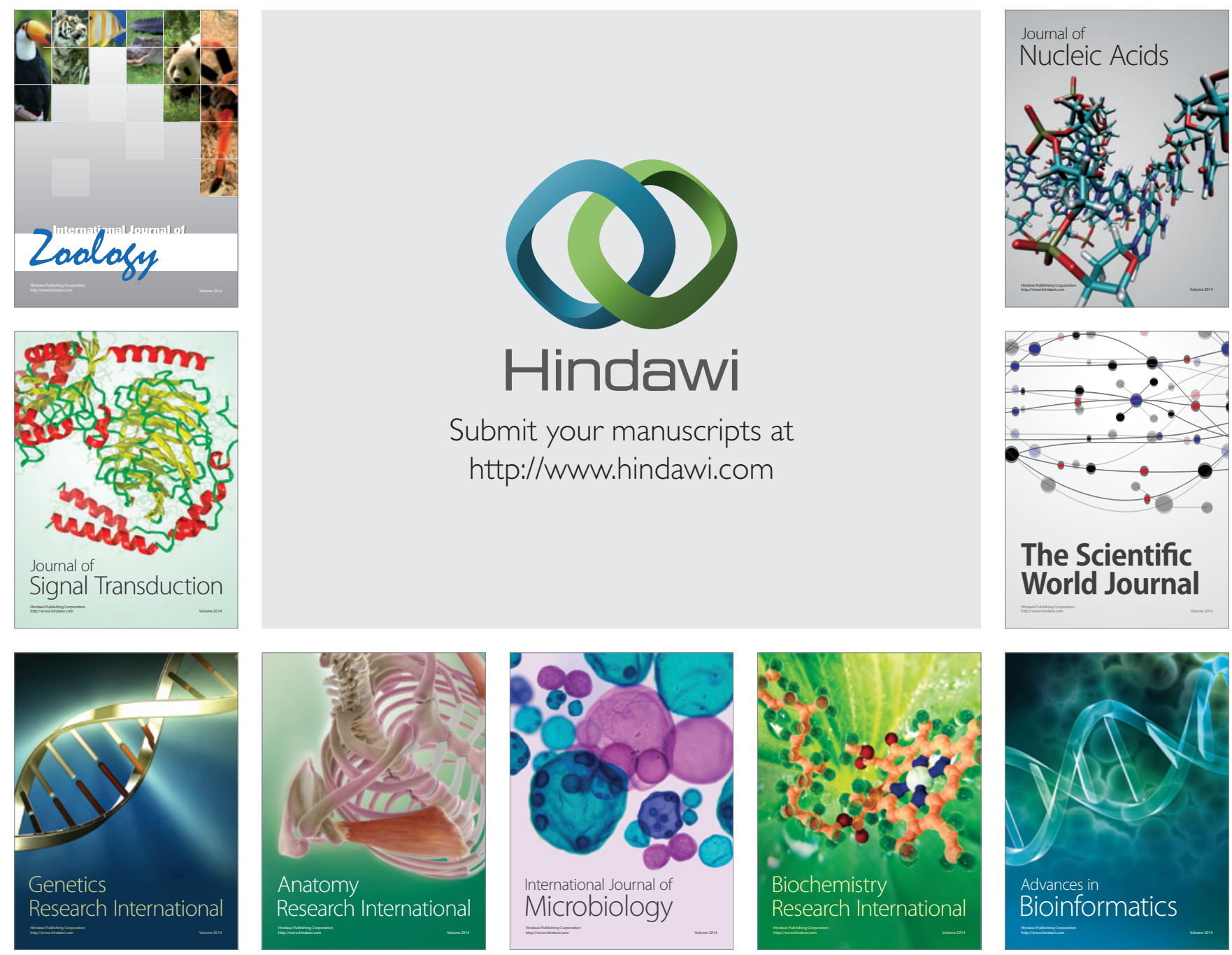

The Scientific World Journal
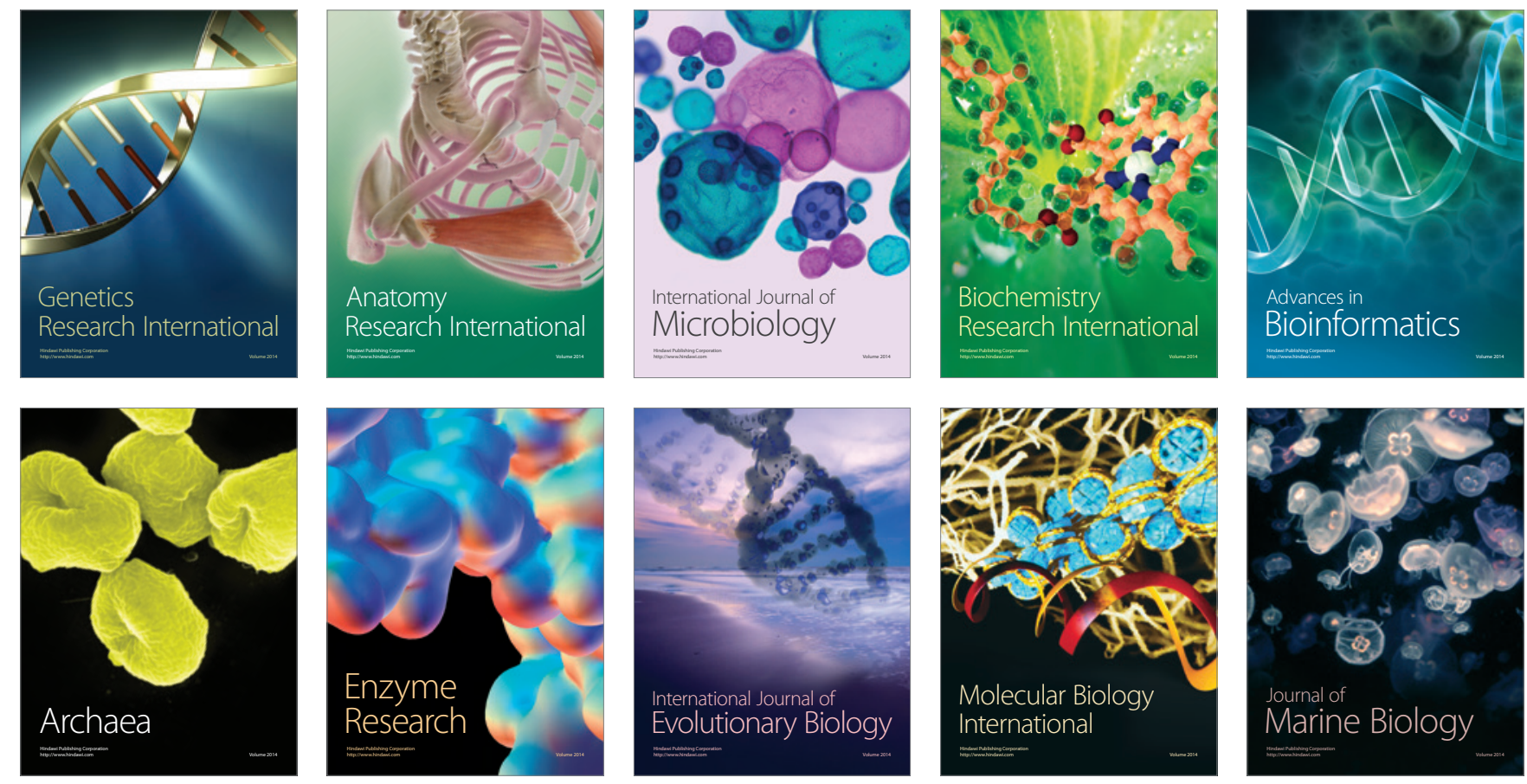